\title{
COMMENTARY
}

\section{DHEA deficiency syndrome: a new term for old age?}

\author{
J P Hinson ${ }^{\mathbf{1}}$ and $\mathbf{P}$ W Raven ${ }^{\mathbf{2}}$ \\ ${ }^{1}$ Molecular and Cellular Biology Section, Division of Biomedical Sciences, St Bartholomew's and the Royal London School of Medicine and Dentistry, \\ Queen Mary and Westfield College, Mile End Road, London E1 4NS, UK \\ ${ }^{2}$ Department of Psychiatry and Behavioural Sciences, Royal Free and University College Medical School, UCL, Royal Free Campus, Rowland Hill Streeet, \\ London NW3 2PF, UK \\ (Requests for offprints should be addressed to J P Hinson)
}

\begin{abstract}
Dehydroepiandrosterone (DHEA) is a steroid secreted by the adrenal cortex, with a characteristic, age-related, pattern of secretion. The decline of DHEA concentrations with age has led to the suggestion that old age represents a DHEA deficiency syndrome and that the effects of ageing can be counteracted by DHEA 'replacement
\end{abstract}

therapy'. DHEA is increasingly being used in the USA, outside medical supervision, for its supposed anti-ageing effects. This commentary weighs the evidence for the existence of a DHEA deficiency syndrome and considers the value of DHEA 'replacement therapy'.

Journal of Endocrinology (1999) 163, 1-5

\section{Introduction}

DHEA has been an endocrine paradox for many years: it was found to circulate in extremely high quantities, yet appeared to have no significant biological function and the regulation of its secretion was a matter of speculation. Recently, there has been a resurgence of interest in DHEA, because it has been suggested that it might have anti-ageing effects. In the USA, DHEA is widely available without prescription, and the increase in unsupervised self-administration of this hormone is a cause for concern to many physicians. There have been, however, many claims for its effects as a preventive medication for the diseases associated with older age. So, should we now describe old age as a DHEA deficiency syndrome?

\section{DHEA secretion declines with age}

There is certainly a far lower plasma concentration of DHEA seen in older individuals compared with younger people (Vermuelen 1980, Orentreich et al. 1984). DHEA has a characteristic pattern of secretion through life (Fig. 1). It is the major product of the foetal adrenal (Shackleton 1984), and circulates in high concentrations, but declines rapidly after birth, as the foetal zone atrophies and disappears in the first year of life (de Peretti \& Forest 1976). During childhood, DHEA concentrations remain low, but, 2 years before the onset of puberty, there is a dramatic increase in DHEA secretion, termed the 'adrenarche'

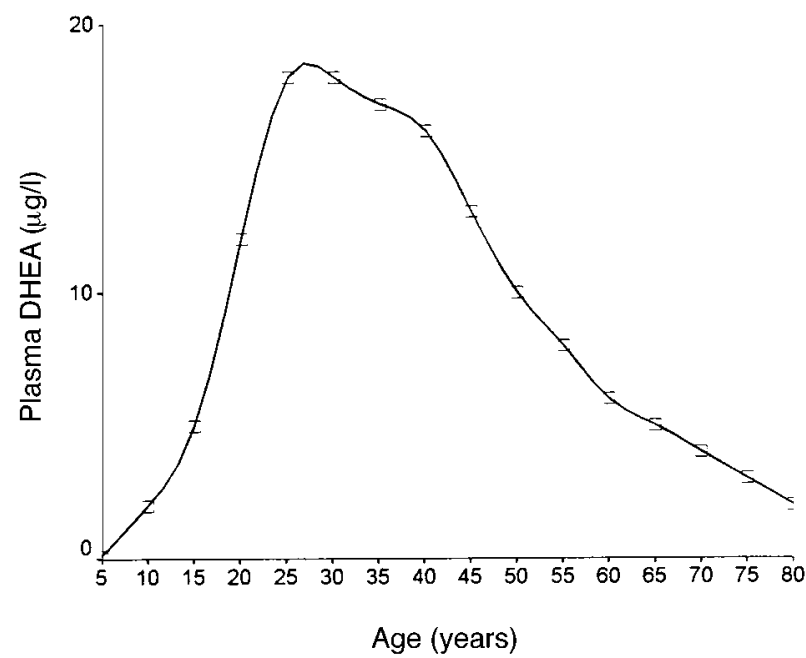

Figure 1 Age-related changes in plasma DHEA concentrations in men. Data taken from de Peretti \& Forest (1976) and Vermuelen (1980).

(Albright 1947). Peak DHEA concentrations are seen in early adulthood, and this is followed by a gradual decline throughout adult life, termed 'adrenopause'. By the age of $70-80$ years, circulating DHEA is only $5-10 \%$ of peak values (Orentreich et al. 1984). This is in contrast to the other adrenocortical hormones, which do not exhibit significant age-related changes. Thus there appears to be a prima facie case for old age representing a state of relative 
DHEA deficiency. Is there, though, any evidence that diminished blood concentrations of DHEA have any associated pathology?

\section{Low plasma DHEA is associated with disease}

Most of the DHEA circulating in blood is in the sulphated form (DHEAS) reflecting the adrenocortical secretion (Van de Weile et al. 1963). Conventional wisdom dictates that only the free DHEA is biologically active, although recent studies on the putative DHEA receptor call this into question. It has been suggested that DHEAS may act as a large plasma reservoir of hormone (Shealy 1995), thus obviating the need for tight regulation of adrenocortical production of DHEA. The long half-life of DHEAS in blood supports this hypothesis (Poortman et al. 1980). Most studies measuring serum hormone concentrations do not make a particular distinction between DHEA and DHEAS. This may be appropriate, as DHEA and DHEAS appear to be freely interconverted by extraadrenal sulphotransferase and sulphatase activity (Arlt et al. 1998). However, it does not take into account the possibility of active regulation of these enzymes.

There have been many studies that have looked at either plasma DHEA or DHEAS concentrations in a range of disease states. There are difficulties presented by such studies, the major of these being the great range of 'normal' DHEA concentrations found, even within a single age and sex grouping (Orentreich et al. 1984). Despite this, there is a remarkable consistency to the data obtained from these studies; DHEA concentrations were found to be significantly decreased in all the conditions investigated, including various cancers, inflammatory diseases, type II diabetes mellitus and cardiovascular disorders (for review, see Shealy 1995). The only exception appears to be Major Depression, a disorder with significant adrenocortical involvement, in which both increased (Heuser et al. 1998) and decreased (Goodyer et al. 1996) DHEA concentrations have been reported. Two recent studies have been carried out on DHEA and cardiovascular disease: the first, on a cohort of 1700 men in New England, suggests that low serum DHEAS may be associated with a greater risk of heart disease, independently of other risk factors (Feldman et al. 1998); the second was a prospective study in Sweden, which found that low serum DHEAS was a predictor of cardiovascular mortality, in a 10-year follow-up of survivors of myocardial infarction (Jansson et al. 1998).

In some conditions, measuring crude changes in serum DHEA or DHEAS has not proved useful and so variations to this approach have been used. For example, in elderly people with cognitive impairment, no correlation has been demonstrated between serum DHEA(S) and the cognitive testing scores (Ravaglia et al. 1998), and in a larger study of normal older women there was no relationship found between serum DHEAS and cognitive performance (Yaffe et al. 1998). However, when DHEA is expressed in relation to cortisol concentrations, a pattern emerges of a low DHEA/cortisol ratio associated with increasing cognitive impairment (Kalmijn et al. 1998). This observation is supported by findings of a prospective study of premenopausal women, in which it was found that DHEAS and cortisol concentrations became dissociated, with lower DHEAS concentrations, in women who later developed rheumatoid arthritis before the age of 50 years (Masi et al. 1998). Also, in inflammatory bowel disease, an inverse relationship between DHEAS and cortisol concentrations appears to be a predictor of inflammatory activity (Straub et al. 1998).

There does appear to be an abundance of data suggesting that there are a range of disease states associated with decreased serum DHEA(S) concentrations relative to cortisol. Although it may be argued that low serum DHEA may result from certain illnesses, the data obtained from the prospective studies, in which serum DHEA was significantly decreased before the onset of symptoms, would support the hypothesis of a DHEA deficiency syndrome. Clearly, this putative deficiency syndrome is not exclusively a condition of old age, but is associated with a range of pathologies, involving, most obviously, the immune system.

\section{How can DHEA concentrations be increased?}

The above findings inevitably lead to the question of the regulation of DHEA secretion. While corticotrophin (ACTH) is undoubtedly capable of stimulating DHEA secretion, the dissociation between cortisol and DHEA in a variety of physiological and pathological conditions suggests that ACTH is not the sole regulator of adrenal androgen secretion (for review, see Parker \& Odell 1980). Thus, in the late 1970 s, there began a quest to find the 'adrenal androgen stimulating hormone'. The quest was unsuccessful. Various candidates and regulatory mechanisms were proposed, then discounted because they failed to account for some aspect of the characteristic pattern of DHEA secretion seen throughout life (McKenna \& Cunningham 1991). The physiological regulation of DHEA secretion therefore remains unclear and fails to give any clues about the possible causes of DHEA deficiency. Despite our lack of understanding of the regulation of DHEA, two patents have recently been taken out in the USA on different methods for increasing serum DHEA concentrations. The earlier patent (number 5609 617; issued March 1997) bypasses the adrenal gland, and involves the topical application of progesterone, accompanied by electronic stimulation of specific acupuncture points on the body. The more recent patent (number 5753 696; issued May 1998), however, is for a cocktail that is purported to enhance serum DHEA concentrations. 
The cocktail comprises three substances, none of which is a steroid: methyl sulphonyl methane, vitamin $\mathrm{C}$ and $\beta-1,3$-glucan. The mechanism by which the combination of these agents might affect DHEA remains obscure and, as yet, unpublished in the scientific literature. Both these patented methods seem bizarre, but clearly there is much interest in increasing serum DHEA concentrations. This is most easily achieved by taking oral DHEA, as many Americans are currently doing. Is there, however, any evidence that correcting 'DHEA deficiency' has a beneficial effect?

\section{DHEA 'replacement' studies}

There have been several studies looking at the effects of DHEA administration, both in animals and in people (for review, see Svec \& Porter 1998). Some studies have been designed to determine whether DHEA may be useful in the treatment of the various different disorders in which a decreased serum DHEA has been demonstrated. One condition in which DHEA treatment appears to have clear beneficial effects is systemic lupus erythematosus (SLE), in which DHEA has been shown to cause an improvement in the condition and allow a reduction in concurrent glucocorticoid doses (vanVollenhoven et al. 1998, Barry et al. 1998). It has also been suggested that DHEA may protect against the osteoporosis seen with glucocorticoid treatment in SLE (Formiga et al. 1997). When administered topically, as a skin cream, to healthy postmenopausal women, DHEA was also found to cause an increase in bone density (Labrie et al. 1997). The authors suggest that DHEA may be a useful form of hormone replacement therapy (HRT) in postmenopausal women, as it had oestrogenic effects on the vagina, without the unwanted endometrial actions of oestrogen HRT (Labrie et al. 1997).

The one study that looked at the effects of 3-month oral DHEA 'replacement' in older, healthy people found that the only significant change in biochemical markers was an increased serum IGF-1. However, the group receiving DHEA reported a greatly increased sense of physical and psychological well-being compared with the placebo control group (Morales et al. 1994). Shorter-term studies have failed to demonstrate any beneficial effect on cognitive function or perceived well-being (Wolf et al. 1997). This perhaps is the crux of the problem with DHEA. It appears that the duration and timing of treatment is important. The route of administration of the DHEA may also be critical: when it was administered by injection, as an adjuvant to influenza vaccination, an increase in the number of responders to the vaccine was observed (Degelau et al. 1997). However, two studies on oral administration produced diametrically opposing results; one demonstrated that, when given orally for 4 days, commencing 2 days before influenza vaccination, no change in response was found (Dannenberg et al. 1997), whereas the other study, in which DHEA was administered at the same time as the vaccination, demonstrated an increased response (Evans et al. 1996).

Thus there is little consensus on the benefits of DHEA replacement therapy. Although low levels of DHEA may predispose to certain diseases, lack of DHEA does not, in itself, appear to cause the diseases. In even the most optimistic studies, DHEA administration did not result in cure, but just in a more effective treatment. Most of the studies to date have been relatively short-term, and not all have been appropriately placebo controlled. We await with interest the results from longer-term replacement studies. From the data available on serum DHEA concentrations in different disease states, it may be predicted that DHEA may have a more important role as a preventive agent than as a treatment for established disease.

\section{Is DHEA 'deficiency' an endocrine disorder?}

In order for DHEA deficiency to be classified as an endocrine disorder, DHEA would need a clear status as a hormone. Hormones are usually defined by three characteristics: their secretion by ductless glands, their transport in blood, and their action through specific receptors. Clearly, DHEA satisfies the first two criteria, but the question of a specific DHEA receptor is a matter of some controversy. There is evidence that DHEA can interact with several different classes of receptor, and there appears to be a considerable degree of tissue and species variation in the receptor type mediating the response to DHEA. In the rat mammary gland, for example, DHEA appears to interact with androgen receptors (Gatto et al. 1998, Sourla et al. 1998) to induce either growth or inhibition of growth, whereas, in the human breast cancer cell line, MCF-7, DHEA has been reported to act through either the oestrogen receptor (Liberato et al. 1993) or the androgen receptor (Boccuzzi et al. 1993). It has been suggested that the hormonal environment may influence the receptor type with which DHEA interacts (Ebeling \& Koivisto 1994), which may explain some apparent discrepancies. Despite being widely reported to have antiglucocorticoid effects, it does not appear that, in the liver, DHEA either binds to the glucocorticoid receptor (McIntosh et al. 1993) or changes glucocorticoid receptor expression (Browne et al. 1993). In the brain, DHEAS, but not DHEA, binds to the picrotoxin site of the gammaamino butyric acid $\left(\mathrm{GABA}_{\mathrm{A}}\right)$ receptor (Sousa \& Ticku 1997). There is also evidence that DHEA binds to the $\mathrm{N}$-methyl-D-aspartate (NMDA) receptor in the rat brain (Monnett et al. 1995).

Specific DHEA binding has been detected in a variety of species and tissues, including: mouse $\mathrm{T}$ cells (Meikle et al. 1992), the mouse B16 melanoma cell line (Kawai et al. 1995), a human T-lymphoid cell line (Okabe et al. 1995), and rabbit vascular smooth muscle cells (Furutama 
et al. 1998). This would suggest the possibility of a specific DHEA receptor, although, to date, this has not been confirmed. DHEA and its sulphate therefore appear to have the capacity to bind to several different receptor types. It is noteworthy that DHEA and DHEAS appear to have different binding properties at the $\mathrm{GABA}_{\mathrm{A}}$ receptor, and there may also be a DHEAS-specific receptor in rat liver (Yamada et al. 1994). Clearly, a great deal of research is still needed to be carried out on the mechanism of action of DHEA and DHEAS at the receptor level.

Perhaps the most compelling evidence against the existence of a syndrome of DHEA deficiency comes from the apparent absence of significant pathology in patients receiving cortisol and fludrocortisone after bilateral adrenalectomy. From the studies outlined above, it might be expected that this group of patients would have a high prevalence of cardiovascular or immunological diseases. However, this does not appear to be the case.

\section{Conclusion}

Despite the lack of a base of evidence to support the concept of DHEA replacement therapy, a massive, uncontrolled and unregulated experiment is currently under way in the United States. There, DHEA is classified as a food supplement and is not only easily available, but is being marketed with unsubstantiated claims for its anti-ageing properties. The explosion in the use of DHEA has been partly due to the new medium of the internet, which has increased available outlets. It can only be a matter of time before widespread DHEA self-administration reaches Europe. As we have seen, the short-term effects of DHEA administration remain controversial, the mechanism of its action is poorly understood and possible adverse effects of its long-term use are, as yet, unrecorded. It is time that science took a lead in informing public opinion.

\section{References}

Albright F 1947 Osteoporosis. Annals of Internal Medicine 27 861-882. Arlt W, Justl H-G, Callies F, Reincke M, Hübler D, Oettel M, Ernst M, Schulte HM \& Allolio B 1998 Oral dehydroepiandrosterone for adrenal androgen replacement: pharmacokinetics and peripheral conversion to androgens and estrogens in young healthy females after dexamethasone suppression. Journal of Clinical Endocrinology and Metabolism 83 1928-1934.

Barry NN, McGuire JL \& vanVollenhoven RF 1998 Dehydroepiandrosterone in systemic lupus erythematosus: relationship between dosage, serum levels and clinical response. Journal of Rheumatology 25 2352-2356.

Boccuzzi G, Dimonaco M, Brignardello E, Leonardi I, Gatto V, Pizzini A \& Gallo M 1993 Dehydroepiandrosterone antiestrogenic action through androgen receptor in MCF-7 human breast cancer cell line. Anticancer Research 13 2267-2272.

Browne ES, Porter JR, Correa G, Abadie J \& Svec F 1993 Dehydroepiandrosterone regulation of the hepatic glucocorticoid receptor in the Zucker rat - the obesity research-program. Journal of Steroid Biochemistry and Molecular Biology 45 517-524.
Dannenberg HD, Ben-Yehuda, Zakay-Rones Z, Gross DJ \& Friedman G 1997 Dehydroepiandrosterone treatment is not beneficial to the immune response to influenza in elderly subjects. Journal of Clinical Endocrinology and Metabolism 82 2911-2914.

Degelau J, Guay D \& Hallgren H 1997 The effect of DHEAS on influenza vaccination in aging adults. Journal of the American Geriatric Society 45 747-751.

Ebeling P \& Koivisto VA 1994 Physiological importance of dehydroepiandrosterone. Lancet 343 1479-1481.

Evans TG, Judd ME, Dowell T, Poe S, Daynes RA \& Araneo BA 1996 The use of oral dehydroepiandrosterone sulfate as an adjuvant in tetanus and influenza vaccination of the elderly. Vaccine $\mathbf{1 4}$ 1531-1537.

Feldman HA, Johannes CB, McInlay JB \& Longcope C 1998 Low dehydroepiandrosterone sulfate and heart disease in middle-aged men: cross-sectional results from the Massachusetts male aging study. Annals of Epidemiology 8 217-228.

Formiga F, Moga I, Nolla JM, Navarro MA, Bonnin R \& Roigescofet D 1997 The association of dehydroepiandrosterone sulphate levels with bone mineral density in systemic lupus erythematosus. Clinical and Experimental Rheumatology 15 387-392.

Furutama D, Fukui R, Amakawa M \& Ohsawa N 1998 Inhibition of migration and proliferation of vascualr smooth muscle cells by dehydroepiandrosterone sulfate. Biochimica et Biophysica Acta 1406 107-114.

Gatto V, Aragno M, Gallo M, Tamagno E, Martini A, Dimonaco M, Brignardello E \& Boccuzzi G 1998 Dehydroepiandrosterone inhibits the growth of DMBA-induced rat mammary carcinoma via the androgen receptor. Oncology Reports 5 241-243.

Goodyer IM, Herbert J, Altham PME, Pearson J, Secher SM \& Shiers HM 1996 Adrenal secretion during major depression in 8- to 16-year olds. I Altered diurnal rhythms in salivary cortisol and dehydroepiandrosterone (DHEA) at presentation. Psychological Medicine 26 245-256.

Heuser I, Deuschle M, Luppa P, Schweiger U, Standhardt H \& Weber B 1998 Increased diurnal plasma concentrations of dehydroepiandrosterone in depressed patients. Journal of Clinical Endocrinology and Metabolism 83 3130-3133.

Jansson JH, Nilsson TK \& Johnson O 1998 von Willebrand factor, tissue plasminogen activator and dehydroepiandrosterone sulphate predict cardiovascular death in a 10 year follow up of survivors of acute myocardial infarction. Heart 80 334-337.

Kalmijn S, Launer LJ, Stolk RP, deJong FH, Pols HAP, Hofman A, Breteler MMB \& Lamberts SWJ 1998 A prospective study on cortisol, dehydroepiandrosterone sulfate and cognitive function in the elderly. Journal of Clinical Endocrinology and Metabolism $\mathbf{8 3}$ 3487-3492.

Kawai S, Yahata N, Nishida S, Nagai K \& Mizushima Y 1995 Dehydroepiandrosterone inhibits B16 mouse melanoma cell growth by induction of differentiation. Anticancer Research 15 427-431.

Labrie F, Diamond P, Cusan L, Gomez J-L, Bélanger A \& Candas B 1997 Effect of 12-month dehydroepiandrosterone replacement therapy on bone, vagina and endometrium in postmenopausal women. Journal of Clinical Endocrinology and Metabolism $\mathbf{8 2}$ 3498-3505.

Liberato MH, Sonohara S \& Brentani MM 1993 Effects of androgens on proliferation and progesterone-reeptor levels in T47D human breast cancer cells. Tumor Biology 14 38-45.

McIntosh MK, Pan JS \& Berdanier CD 1993 In vitro studies on the effects of dehydroepiandrosterone and corticosterone on hepaticsteroid receptor-binding and mitochondrial respiration. Comparative Biochemistry and Physiology 104 147-153.

McKenna TJ \& Cunningham SK 1991 The control of adrenal androgen secretion. Journal of Endocrinology 129 1-3.

Masi AT, Chatterton RT, Fecht T, Aldag JC, Comstock GW, Helzlsouer KJ, Hoffman SC \& Malamet RL 1998 Dissociation of serum dehydroepiandrosterone sulfate (DHEAS) and cortisol levels 
in younger premenopausal women prior to onset of rheumatoid arthritis (RA) before age 50: results of a prospective, controlled study. Arthritis and Rheumatism 41559.

Meikle AW, Dorchuck RW, Araneo BA, Stringham JD, Evans TG, Spruance SL \& Daynes RA 1992 The presence of a dehydroepiandrosterone-specific receptor-binding complex in murine T-cells. Journal of Steroid Biochemistry and Molecular Biology $\mathbf{4 2}$ 293-304.

Monnet FP, Mahe V, Robel P \& Baulieu EE 1995 Neurosteroids, via sigma receptors, modulate the $\left[{ }^{3} \mathrm{H}\right]$ norepinephrine release evoked by $N$-methyl-D-aspartate in rat hippocampus. Proceedings of the National Academy of Sciences of the USA 92 3773-3778.

Morales AJ, Nolan JJ, Nelson JC \& Yen SSC 1994 Effects of replacement dose of dehydroepiandrosterone in men and women of advancing age. Journal of Clinical Endocrinology and Metabolism 78 1360-1367.

Okabe T, Haji M, Takayanagi R, Adachi M, Imasaki K, Kurimoto F, Watanabe T \& Nawata H 1995 Up-regulation of high-affinity dehydroepiandrosterone binding-activity by dehydroepiandrosterone in activated human T-lymphocytes. Journal of Clinical Endocrinology and Metabolism $802993-2996$.

Orentreich N, Brind JL, Rizer RL \& Vogelman JH 1984 Age changes and sex differences in serum dehydroepiandrosterone sulfate concentrations throughout adulthood. Journal of Clinical Endocrinology and Metabolism 59 551-555.

Parker LN \& Odell WD 1980 Control of adrenal androgen secretion. Endocrine Reviews $1392-410$.

de Peretti E \& Forest MG 1976 Unconjugated dehydroepiandrosterone plasma levels in normal subjects from birth to adolescence in human: the use of a sensitive radioimmunoassay. Journal of Clinical Endocrinology and Metabolism 43 982-991.

Poortman J, Andriesse R, Agema A, Donker GH, Schwarz F \& Thijssen THH 1980 In Adrenal Androgens, pp 219-240. Eds AR Genazzani, JHH Thijssen \& PK Siiteri. New York: Raven Press.

Ravaglia G, Forti P, Maioli F, Boschi F, DeRonchi D, Bernardi M, Pratelli L, Pizzoferrato A \& Cavalli G 1998 Dehydroepiandrosterone sulphate and dementia. Archives of Gerontology and Geriatrics S6 423-426.

Shackleton CHL 1984 Steroid synthesis and catabolism in the fetus and neonate. In Biochemistry of Steroid Hormones, pp 441-447. Ed HJL Makin. Oxford: Blackwell Scientific.

Shealy CN 1995 A review of dehydroepiandrosterone (DHEA). Integrative Physiological and Behavioral Science 30 308-313.
Sourla A, Martel C, Labrie C \& Labrie F 1998 Almost exclusive androgenic action of dehydroepiandrosteone in the rat mammary gland. Endocrinology 139 753-764.

Sousa A \& Ticku MK 1997 Interactions of the neurosteroid dehydroepiandrosterone sulfate with the GABA(A) receptor complex reveals that it may act via the picrotoxin site. Journal of Pharmacology and Experimental Therapeutics 282 827-833.

Straub RH, Vogl D, Gross V, Lang B, Scholmerich J \& Andus T 1998 Association of humoral markers of inflammation and dehydroepiandrosterone sulfate or cortisol serum levels in patients with chronic inflammatory bowel disease. American Journal of Gastroenterology 93 2197-2202.

Svec F \& Porter JR 1998 The actions of exogenous dehydroepiandrosterone in experimental animals and humans. Proceedings of the Society for Experimental Biology and Medicine 218 174-191.

Van de Weile RL, MacDonald PC, Gurpide E \& Leiberman S 1963 Studies on the secretion and interconversion of the androgens. Recent Progress in Hormone Research 19 275-310.

vanVollenhoven RF, Morabito LM, Engleman EG \& McGuire JL 1998 Treatment of systemic lupus erythematosus with dehydroepiandrosterone: 50 patients treated up to 12 months. Journal of Rheumatology 25 285-289.

Vermuelen A 1980 Adrenal androgens and aging. In Adrenal Androgens, pp 207-217. Eds AR Genazzani, JHH Thijssen \& PK Siiteri. New York: Raven Press.

Wolf OT, Neumann O, Hellhammer DH, Geiben AC, Strasburger CJ, Dressendorfer RA, Pirke KM \& Kirschbaum C 1997 Effects of two week physiological dehydroepiandrosterone substitution on cognitive performance and well-being in healthy elderly women and men. Journal of Clinical Endocrinology and Metabolism 82 2363-2367.

Yaffe K, Ettinger B, Pressman A, Seeley D, Whooley M, Schaefer C \& Cummings S 1998 Neuropsychiatric function and dehydroepiandrosterone sulfate in elderly women: a prospective study. Biological Psychiatry 43 694-700.

Yamada J, Sugiyama H, Sakuma M \& Suga T 1994 Specific binding of dehydroepiandrosterone-sulfate to rat liver cytosol - a possible association with peroxisomal enzyme-induction. Biochimica et Biophysica Acta 1224 139-146.

Received 8 March 1999

Accepted 8 June 1999 